$\begin{gathered}\text { Revista do Departamento de Geografia } \\ \text { Universidade de São Paulo } \\ \text { Www.revistas.usp.br/rdg } \\ \text { ISSN 2236-2878 }\end{gathered}$
V.34 (2017)

\title{
Avaliação do Potencial Geoturístico no Território da Proposta Geoparque Quarta Colônia
}

\section{Evaluation of Geotourism Potential of the Geopark Proposal Quarta Colônia / Rio Grande Do Sul}

\author{
Djulia Regina Ziemann \\ Universidade Federal de Santa Maria \\ djuliaziemann@gmail.com \\ Adriano Severo Figueiró \\ Universidade Federal de Santa Maria \\ adri.geo.ufsm@gmail.com
}

Resumo: O geoturismo permite um novo olhar à visitação turística de ambientes naturais, indo além da mera contemplação da paisagem, permitindo a interpretação do geopatrimônio visitado. Caracteriza-se como uma atividade capaz de contribuir não apenas com a promoção e conservação geopatrimonial, mas, também, com o desenvolvimento local da comunidade onde esta atividade ocorre. O presente trabalho relata uma proposta de quantificação do geopatrimônio da região da Quarta Colônia, localizada na porção central do Rio Grande do Sul, com avaliação do Índice de Aproveitamento Geoturístico e do Risco de Degradação. Após a avaliação foi possível identificar que, 24 locais podem ser considerados como apropriados para a utilização geoturística, enquanto 19 locais ainda necessitam de maiores investimentos para seu melhor aproveitamento, em que pese o fato de que todos os geossítios apresentam potencialidade para o desenvolvimento do geoturismo e de estratégias de geoconservação. A variação dos resultados aponta para a necessidade de medidas de intervenção primárias e políticas públicas que melhorem a sua gestão.

Palavras-chave: Avaliação do Geopatrimônio. Geoconservação. Quantificação. Geoturismo.

\begin{abstract}
Geotourism allows a new look at the tourist visitation of natural environments, going beyond the contemplation of the landscape, allowing the interpretation of the geoheritage visited. It is characterized as an activity capable of contributing not only to geoheritage promotion and conservation, but also to the local development of the community where this activity takes place. The present work reports a proposal of quantification of geoheritage of the Quarta Colônia, located in the central portion of Rio Grande do Sul, with evaluation of the geotourism utilization index and the risk of degradation. After the evaluation it was possible to identify that, 24 geosites can be considered suitable for geotourism use, while 19 geosites still need more investments for their better use, despite the fact that all geosites have potential for the development of geotourism and geoconservation strategies. The variation of results points to the need for primary intervention measures and public policies that improve management.
\end{abstract}

Keywords: Evaluation of the Geoheritage. Local development. Quantification. Geotourism. 


\section{INTRODUÇÃO}

A proposta Geoparque Quarta Colônia abrange uma área localizada na Mesorregião Centro-Oriental Rio-Grandense, e envolve nove municípios gaúchos: Agudo, Dona Francisca, Faxinal do Soturno, Ivorá, Nova Palma, Pinhal Grande, Restinga Seca, São João do Polêsine e Silveira Martins, em uma área total de $2.923 \mathrm{Km}^{2}$ (Figura 1). Seja pelas características paisagísticas de transição do Planalto Meridional Brasileiro para o Pampa (GODOY et al., 2012), seja pelos aspectos culturais vinculados à colonização italiana e alemã.

Esta paisagem da Quarta Colônia integra com muita sintonia a riqueza biótica dos últimos remanescentes de floresta estacional caducifólia da região com a grande variação geomorfológica dos vales encaixados e escarpas rochosas da Formação Serra Geral e a imensa diversidade cultural associada ao intenso calendário de festividades e eventos religiosos, como romarias, procissões e festas em homenagem aos padroeiros. A gastronomia traz às casas e às festividades, mesas fartas com sopa de agnoline, risoto, queijo, pães, cucas, vinho colonial, chope, salame, geléias (schimier do alemão) e diversas outras iguarias tradicionais (LORO; COELHO, 2010 e SANTOS et al. 2015) que representam um insumo fundamental ao fomento da atividade turística.

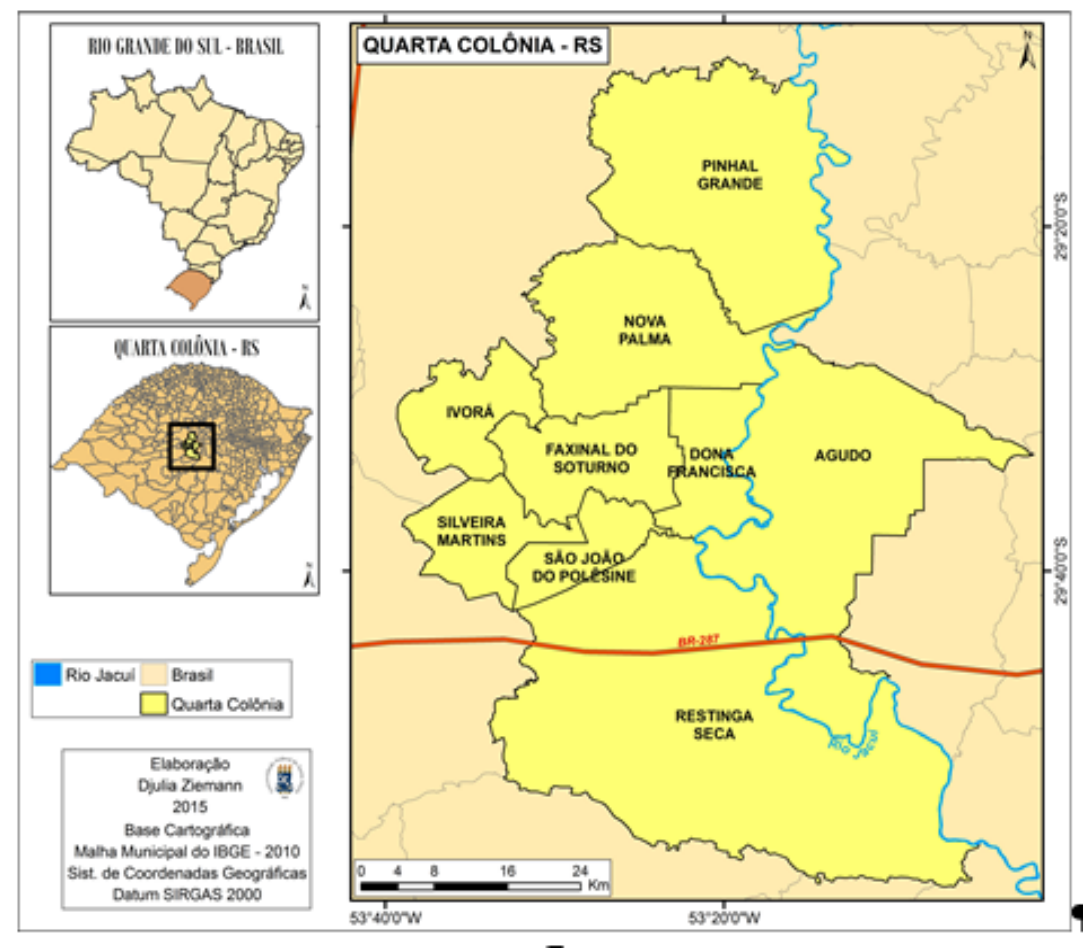

Figura 1: Mapa de localização da área de estudo - Projeto Geoparque Quarta Colônia (RS). Fonte: Adaptado de IBGE (2015).

Do ponto de vista geológico, esta área compreende uma parte da Bacia do Paraná, que evoluiu no Rio Grande do Sul desde o Período Permiano ao Cretáceo. As rochas, nas porções mais baixas do território (área da Depressão Central), são arenitos, siltitos e argilitos fossiliferos, representativos do Período Triássico (Formações Santa Maria e Caturrita); estratigraficamente acima, estão os arenitos eólicos (Formação Botucatu) e, compondo a porção mais alta e recobrindo todo o Planalto, os basaltos da Formação Serra Geral, registro de um dos mais volumosos eventos ígneos da história do planeta (ZERFASS, 2007).

Em se tratando da história da vida na Terra, a região guarda fósseis triássicos de importância internacional, representados por belos exemplares de vertebrados, que compreendem desde pequenos esfenodontes e procolofonídeos, dinossauros basais, delicados registros de flores, troncos e ramos de coníferas, além de rastros de vários icnogêneros (LANGER et al., 2007).

As proeminentes potencialidades deste território ainda não são exploradas do ponto de vista geoturístico, o que levou o Consórcio de Desenvolvimento Sustentável da Quarta Colônia (CONDESUS), em 2008, a solicitar ao Serviço Geológico do Brasil - Companhia de Pesquisas em 
Recursos Minerais (CPRM), a realização de um inventário geopatrimonial do território para qualificar a atividade turística então existente. Realizou-se pelo Serviço Geológico do Brasil, com apoio de universidades do estado, um relatório técnico do patrimônio geológico identificado a fim de utilizá-lo, posteriormente, como base para a elaboração de um dossiê de candidatura para a criação de um futuro geoparque. Contudo, o inventário realizado pautou-se somente nos valores científicos do patrimônio e em um número reduzido de locais, anteriormente conhecidos em estudos geológicos/paleontológicos, negligenciando aspectos culturais e geoturísticos significativos que se apresentam naquele território, o que acabou por reduzir os potenciais de desenvolvimento que poderiam ser agregados à proposta de um futuro geoparque, cujo objetivo, segundo a UNESCO, além de principalmente garantir a conservação patrimonial, é o de promover o desenvolvimento local das comunidades com base na promoção do geopatrimônio (FARSANI et al., 2011).

Faz-se de suma importância ressaltar, que este trabalho se apoia na definição de geopatrimônio expressa por Valcarce e Cortés (1996, p.11), que o definem como: "um conjunto de recursos naturais não renováveis, de valor científico, cultural ou educativo, que permitem conhecer, estudar e interpretar a evolução da história geológica da Terra e os processos que a modelaram". Considerando-se também a abordagem mais integradora, denotada por Borba (2011), que opta por considerar como sinônimos os termos patrimônio geológico e geopatrimônio, justificando a preferência pelo uso do segundo para fins de facilitar a associação do prefixo "geo" pelo público leigo.

A discussão denotada neste artigo, tem como objetivo geral apresentar uma nova proposta de quantificação do geopatrimônio para os geossítios da proposta de Geoparque Quarta Colônia. E como objetivos específicos: a) identificar novos geossítios, b) hierarquizar os geossítios selecionados em cada categoria.

\section{METODOLOGIA}

De acordo com Brilha (2005), uma estratégia de geoconservação deve sistematizar tarefas no âmbito da conservação do geopatrimônio de uma dada área. Tais tarefas devem ser agrupadas em etapas sequenciais de compreensão do patrimônio, envolvendo: realização de inventário, avaliação quali-quantitativa, enquadramento legal, conservação, divulgação e monitoramento. No presente trabalho abordar-se-á as etapas referentes à realização de inventário e quantificação (Figura 2).

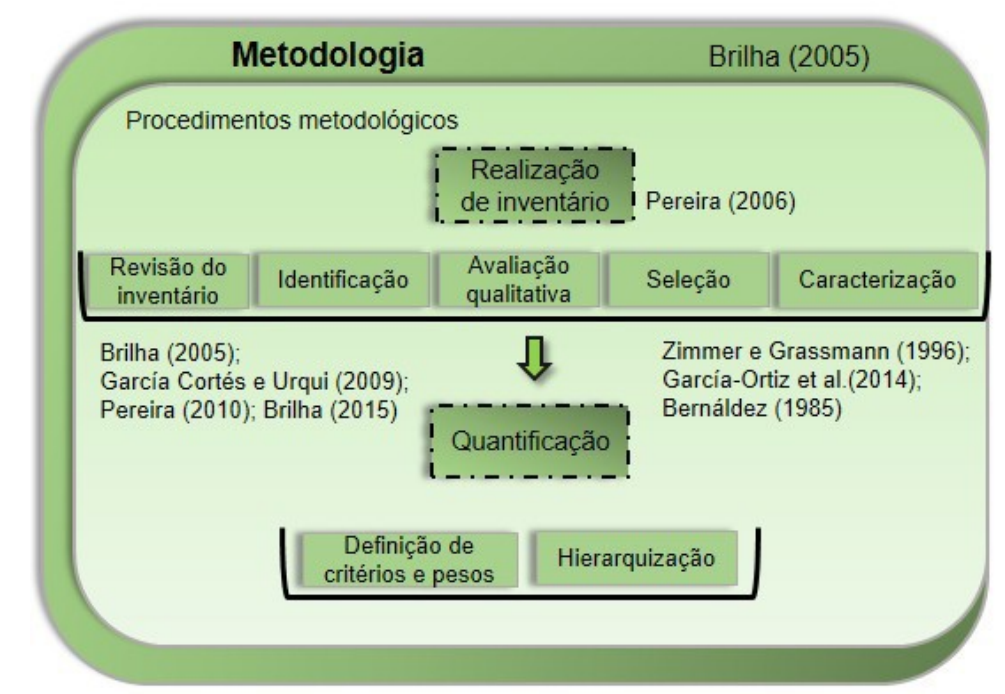

Figura 2: Diagrama das etapas metodológicas da pesquisa. Fonte: ZIEMANN (2016).

\subsection{Realização de inventário}

A primeira etapa deste trabalho consistiu na revisão dos 20 geossítios anteriormente inventariados pela equipe técnica da CPRM (GODOY et al.,2012). Para a realização desta etapa foi utilizada nos trabalhos de campo a ficha da ProGEO-Portugal e adotada a metodologia proposta por Pereira (2006), com adaptações a partir das seguintes sub-etapas: 
(i) Identificação: foram identificados locais com potencial interesse geoturístico e científico/didático. Para a identificação dos locais de interesse científico/didático, foram consultados pesquisadores Lima et al (2010), dos departamentos de Biodiversidade Animal e Geociências da Universidade Federal de Santa Maria, enquanto que para a identificação de locais de interesse turístico, foram consultados o CONDESUS e as secretarias municipais relacionadas ao turismo, dos 9 municípios em questão. Nesta sub-etapa, também foi realizado o amplo levantamento de publicações que pudessem sinalizar potenciais geossítios a serem elencados no inventário preliminar. As consultas renderam 39 novos locais de interesse turístico.

(ii) Avaliação qualitativa: a avaliação qualitativa foi realizada a partir de critérios previamente definidos, como tipos de interesse (científico, didático, cultural e geoturístico), uso potencial (acessibilidade, visibilidade e vulnerabilidade) e valor adicional (recreativo, religioso, ecológico e arqueológico/paleontológico). Estes critérios foram avaliados em alto, médio e baixo ou bom, moderado e ruim. Durante a identificação dos prováveis geossítios constatou-se um elevado número de locais cujo maior interesse patrimonial estava associado à ocorrência de quedas d'água. Como os critérios estabelecidos para a primeira avaliação dos geossítios não permitiram uma discriminação significativa entre as 13 quedas d'água encontradas, devido ao alto grau de homogeneidade estrutural destes geossítios, foi necessário estabelecer uma segunda avaliação, incluindo outros critérios de análise que permitissem a discriminação entre as cascatas consideradas com valor geopatrimonial e aquelas que foram consideradas apenas como elementos da geodiversidade local. Os critérios adotados para avaliar quali-quantitativamente as quedas d'água foram: altura da queda ( $>30 \mathrm{~m}$; entre $10-30 \mathrm{~m} ;<10 \mathrm{~m})$, volume de água durante o ano (cobre totalmente a queda; cobre parcialmente a queda; cobre pontualmente a queda), possibilidade de banho/balneabilidade (existente/inexistente), existência de falhas transversais que proporcionam a mudança de direção da água (existente; inexistente), profundidade visual da água relacionada à turbidez e cor (transparente; turva; opaca).

(iii) Seleção dos locais: Com base nos indicadores descritos na etapa anterior, dos 39 novos locais identificados, foram selecionados 23 locais com melhores parâmetros de avaliação para uso geoturístico, somaram-se a estes locais, os 20 geossítios de valor cinetífico significativo, anteriormente inventariados pela CPRM, totalizando, assim, 43 locais com valor patrimonial dentro da área de estudo, sendo, posteriormente, submetidos à avaliação quantitativa;

(iv) Caracterização dos locais de interesse: Concomitantemente à identificação e seleção dos geossítios, realizou-se o preenchimento das fichas da ProGEO-Portugal, adaptada à realidade brasileira. Assim, para cada local foram levantadas as coordenadas em GPS e foi realizada a recolha de imagens e informações gerais para a caracterização dos geossítios. Enfocando-se na ampliação de informações já existentes, a exposição mais detalhada da identificação dos locais foi priorizada; a avaliação preliminar quanto às condições de observação e a vulnerabilidade do geossítio. A revisão em relação ao tipo de interesse do geossítio (especificamente no caso dos geossítios que já haviam sido inventariados anteriormente e que estavam sendo reavaliados), além de maior descrição sobre o patrimônio cultural envolvido, foram considerados como prioritários.

\subsection{Avaliação quantitativa dos geossítios selecionados}

A elaboração de uma proposta adaptada de quantificação do geopatrimônio, mais adequada à realidade da área de estudo, mostrou-se necessária. Assim, as bases utilizadas foram as propostas pré-existentes de Brilha (2005); García Cortés e Urqui (2009); Pereira (2010) e Brilha (2015). O artigo de García-Ortiz; Fuertes-Gutiérrez e Fernández-Martínez (2014) foi utilizado como base para a definição dos conceitos de sensibilidade, fragilidade e vulnerabilidade (natural ou antrópica). A avaliação do potencial turístico, contou com metodologia apresentada por Zimmer e Grassmann (1996), como base, além de acréscimo de elementos a partir das sugestões de Bernáldez (1985), que discute os valores de caráter estético, emocional e sentimental que justificam a preservação dos entornos naturais.

Durante a revisão destas propostas, expuseram-se categorias, critérios, subcritérios e parâmetros relevantes na avaliação do geopatrimônio, além da inserção de novos elementos, totalizando, ao final, um conjunto de 2 categorias, 6 critérios e 28 subcritérios. Cada critério apresenta um conjunto de subcritérios para descrever a situação e parâmetros expressos em valores que variam entre $0,1,5 \mathrm{e}$ 10 (inexistente, ruim, moderado e bom, para o potencial geoturístico, e inexistente, bom, moderado e ruim para o risco de degradação). 
Considerando o objetivo da pesquisa de selecionar os geossítios da Quarta Colônia com os maiores potenciais de sustentação da atividade geoturística dentro do projeto do geoparque, optou-se por representar as categorias avaliadas em Potencial Geoturístico e Risco de Degradação, aos quais foram agrupados diferentes critérios de quantificação. Na avaliação do Potencial Geoturístico foram avaliados o Valor Geocientífico, Valor Cultural, Valor Estético e Valor de Uso (Quadro 1). Já na categoria Risco de Degradação foram agrupados os critérios: Risco Associado e Estado de Conservação (Quadro 2).

A seguir são demostrados os critérios e subcritérios estabelecidos para a proposta de avaliação desta pesquisa:

Quadro 1: Categorias, critérios, subcritérios e parâmetros envolvidos na quantificação do Valor Geocientífico de determinado geossítio Fonte: ZIEMANN (2016).

\begin{tabular}{|c|c|c|c|c|c|c|c|}
\hline $\begin{array}{l}\text { Potencial } \\
\text { Geoturístico }\end{array}$ & & & Descrição & 0 & 1 (Ruim) & 5 (Moderado) & 10 (Bom) \\
\hline \multirow{7}{*}{$\begin{array}{c}\text { Valor } \\
\text { Geocientifico }\end{array}$} & VG1 & Local tipo & $\begin{array}{c}\text { Indicativo do geossítio ser } \\
\text { considerado como referência na sua } \\
\text { categoria para a área de estudo }\end{array}$ & $\begin{array}{c}\text { Geossítio não é } \\
\text { reconhecido }\end{array}$ & $\begin{array}{l}\text { Geossítio é reconhecido } \\
\text { como local-tipo secundário }\end{array}$ & $\begin{array}{c}\text { Geossítio é reconhecido } \\
\text { como local-tipo na área } \\
\text { de estudo } \\
\end{array}$ & $\begin{array}{c}\text { Geossítio é reconhecido } \\
\text { como local-tipo em nivel } \\
\text { estadual ou nacional }\end{array}$ \\
\hline & VG2 & Raridade & $\begin{array}{l}\text { Importância do local em termos de } \\
\text { ocorrência na área de estudo }\end{array}$ & $\begin{array}{c}\text { Existem mais de } 10 \\
\text { exemplos na área de } \\
\text { estudo }\end{array}$ & $\begin{array}{l}\text { Existem de } 5 \text { a } 10 \text { exemplos } \\
\text { na área de estudo }\end{array}$ & $\begin{array}{c}\text { Existem de 2 a } 4 \\
\text { exemplos na área de } \\
\text { estudo }\end{array}$ & $\begin{array}{l}\text { Só existe um exemplo na } \\
\text { área de estudo }\end{array}$ \\
\hline & VG3 & $\begin{array}{l}\text { Grau de } \\
\text { conhecimento } \\
\text { científico }\end{array}$ & $\begin{array}{l}\text { Expressa a quantidade de } \\
\text { informaçōes científicas publicadas em } \\
\text { relaçâao ao geossitio }\end{array}$ & $\begin{array}{l}\text { Nenhum trabalho } \\
\text { publicado em relação } \\
\text { ao geossitio }\end{array}$ & $\begin{array}{l}\text { Apenas trabalhos para } \\
\text { congressos publicados }\end{array}$ & $\begin{array}{l}\text { Pelo menos uma } \\
\text { tese/dissertação ou um } \\
\text { artigo publicado em } \\
\text { revista internacional ou } \\
\text { nacional } \\
\end{array}$ & $\begin{array}{c}\text { Mais de uma } \\
\text { tese/dissertação e mais } \\
\text { de um artigo publicado } \\
\text { em revista internacional }\end{array}$ \\
\hline & VG4 & Integridade & $\begin{array}{l}\text { Refere-se ao nivel de integridade } \\
\text { (conservação) de todos elementos } \\
\text { geopatrimoniais presentes no } \\
\text { geossitio }\end{array}$ & $\begin{array}{c}\text { O geossítio está } \\
\text { muito deteriorado e } \\
\text { sem possibilidade de } \\
\text { recuperação }\end{array}$ & $\begin{array}{l}\text { O geossítio está deteriorado, } \\
\text { mas permite observação de } \\
\text { alguns elementos } \\
\text { geopatrimoniais e está sem } \\
\text { possibilidade de recuperação }\end{array}$ & $\begin{array}{c}\text { O geossítio está } \\
\text { deteriorado, mas } \\
\text { apresenta possibilidade } \\
\text { de intervenção } \\
\end{array}$ & $\begin{array}{l}\text { O geossítio está sem } \\
\text { qualquer deterioração e } \\
\text { sem necessidade de } \\
\text { recuperação }\end{array}$ \\
\hline & VG5 & $\begin{array}{l}\text { Relevância } \\
\text { didática }\end{array}$ & $\begin{array}{l}\text { Indicativo do potencial do geossítio } \\
\text { ilustrar elementos ou processos da } \\
\text { geodiversidade e possibilidade do uso } \\
\text { para o ensino de alunos da Educação } \\
\text { Básica ou aulas práticas universitárias }\end{array}$ & $\begin{array}{l}\text { Sem relevância } \\
\text { didática }\end{array}$ & $\begin{array}{l}\text { O local pode ser utilizado } \\
\text { para o ensino, porém existem } \\
\text { locais que expressam de } \\
\text { melhor forma o processo da } \\
\text { geodiversidade }\end{array}$ & $\begin{array}{l}\text { O local pode ser utilizado } \\
\text { para público essecifico } \\
\text { universitário }\end{array}$ & $\begin{array}{l}\text { O local pode ser } \\
\text { facilmente utilizado para } \\
\text { vários niveis de ensino }\end{array}$ \\
\hline & VG6 & $\begin{array}{l}\text { Associação de } \\
\text { elementos }\end{array}$ & $\begin{array}{c}\text { Associação de outros valores da } \\
\text { biodiversidade ao geossítio } \\
\text { (visualizados no local ou a partir do } \\
\text { local) }\end{array}$ & $\begin{array}{l}\text { Não há ocorrência } \\
\text { deoutros valores da } \\
\text { biodiversidade }\end{array}$ & $\begin{array}{c}\text { Ocorrência de outros valores } \\
\text { da biodiversidade a menos de } \\
10 \mathrm{~km} \text { de distância do } \\
\text { geossitio }\end{array}$ & $\begin{array}{l}\text { Ocorrência de diversos } \\
\text { valores da biodiversidade } \\
\text { a menos de } 5 \mathrm{~km} \text { de } \\
\text { distância do geossitio } \\
\end{array}$ & $\begin{array}{c}\text { Ocorrência de diversos } \\
\text { valores da biodiversidade } \\
\text { a menos de } 1 \mathrm{~km} \mathrm{de} \\
\text { distância do geossitio }\end{array}$ \\
\hline & VG7 & Acessibilidade & $\begin{array}{l}\text { Indicativo das condições de acesso } \\
\text { ao local }\end{array}$ & $\begin{array}{c}\text { O geossítio está } \\
\text { localizado a menos } \\
\text { de } 100 \mathrm{~m} \text { de estrada } \\
\text { asfaltada }\end{array}$ & $\begin{array}{l}\text { O geossítio está localizado a } \\
\text { menos de } 200 \mathrm{~m} \text { de estrada } \\
\text { asfaltada }\end{array}$ & $\begin{array}{c}\text { O geossítio possui } \\
\text { acesso restrito a estrada } \\
\text { vicinal com acesso por } \\
\text { ônibus }\end{array}$ & $\begin{array}{l}\text { O geossítio possui } \\
\text { acesso por trilhas e } \\
\text { veículos tradicionais }\end{array}$ \\
\hline
\end{tabular}

Considerando que os critérios utilizados não apresentam o mesmo grau de importância na atribuição de valor de um dado geossítio, optou-se por utilizar índices de ponderação dos critérios (Quadro 4), com vistas à obtenção de uma normalização estatística dos valores.

Foram calculadas as ponderações para cada categoria e o Índice de Aproveitamento Geoturístico (IAGtur). O Índice é calculado a partir dos valores obtidos para a categoria de Potencial Geoturístico, somados aos resultados obtidos para o valor geocientífico (20\%), valor cultural (20\%), valor estético $(40 \%)$ e valor de uso (20\%) dos quais são subtraídos os valores obtidos na categoria de Risco de Degradação (calculado a partir do risco associado (50\%) e estado de conservação (50\%), conforme Equação 1:

\section{IAGtur = PGtur - RD}

IAGtur = PGtur $[$ VG (20\%) + VCult (20\%) + VEst (40\%) + VUso (20\%)] - RD [R (50\%)+ C (50\%)] (1)

Onde:

IAGtur = Índice de Aproveitamento Geoturístico

PGtur = Potencial Geoturístico

$V G=$ Valor Geocientífico

VCult $=$ Valor Cultural

VEst = Valor Estético

VUso $=$ Valor de Uso

$\mathrm{RD}=$ Risco de Degradação

$\mathrm{R}=$ Risco Associado

$\mathrm{C}=$ Estado de Conservação 
O potencial geoturístico expressa a atratividade de um determinado geossítio em relação ao potencial dos seus aspectos geológicos, à infraestrutura, à segurança e à possibilidade de interpretação. Evidencia-se, que a utilização turística do local implica em algum risco de degradação, pois as características geopatrimoniais podem sofrer danos ou até mesmo serem completamente destruídas, caso o local não apresente uma gestão adequada. Desta forma, o cálculo auxilia para a seleção de locais onde a potencialidade de uso seja mais equilibrada em relação à possibilidade de degradação, gerando assim um índice de aproveitamento do local.

Após a realização dos cálculos procedeu-se a hierarquização dos resultados para definir os geossítios com maior índice de aproveitamento geoturístico e com maior necessidade de proteção, em função dos valores do Risco de Degradação.

Quadro 2: Categoria, critérios, subcritérios e parâmetros envolvidos na quantificação do valor cultural, estéticoe de uso de determinado geossítio. Fonte: ZIEMANN (2016).

\begin{tabular}{|c|c|c|c|c|c|c|c|}
\hline $\begin{array}{l}\text { Potencial } \\
\text { Geoturistico }\end{array}$ & & & Descrição & 0 & 1 (Ruim) & 5 (Moderado) & 10 (Bom) \\
\hline \multirow{2}{*}{$\begin{array}{l}\text { Valor } \\
\text { cultural }\end{array}$} & Vcult1 & $\begin{array}{l}\text { Valor de } \\
\text { memória }\end{array}$ & $\begin{array}{c}\text { Corresponde à ligação do geossítio } \\
\text { com a história local, por exemplo, } \\
\text { nomeia o local, possui algum mito } \\
\text { ou lenda ou serve de referência para } \\
\text { a localização }\end{array}$ & $\begin{array}{l}\text { O geossítio não } \\
\text { apresenta uma ligação } \\
\text { considerável com a } \\
\text { história local }\end{array}$ & $\begin{array}{l}\text { O geossítio apresenta uma } \\
\text { relação sutil com a história } \\
\text { local, servindo apenas como } \\
\text { referência para a região }\end{array}$ & $\begin{array}{c}\text { O geossítio apresenta ligação } \\
\text { direta com a história local, } \\
\text { sendo utilizado para nomear, } \\
\text { OU como referência } \\
\text { importante para a região ou } \\
\text { possui algum mito/lenda } \\
\text { associado } \\
\end{array}$ & $\begin{array}{c}\text { O geossitio apresenta ligação } \\
\text { direta com a história local, } \\
\text { sendo utilizado para nomear } \mathrm{E} \\
\text { como referenciaia para a região } \mathrm{E} \\
\text { possui algum mito/lenda } \\
\text { associado } \\
\end{array}$ \\
\hline & Vcult2 & $\begin{array}{c}\begin{array}{c}\text { Valor } \\
\text { espiritual }\end{array} \\
\text { es }\end{array}$ & $\begin{array}{l}\text { Refere-se à religiosidade envolvida } \\
\text { com o geossítio }\end{array}$ & $\begin{array}{l}\text { O geossítio não possui } \\
\text { associação religiosa }\end{array}$ & $\begin{array}{c}\text { O geossítio já foi utilizado } \\
\text { para atividades religiosas, } \\
\text { mas devido a suas condiçōes } \\
\text { de conservação não pode } \\
\text { mais ser utilizado sem } \\
\text { alguma intervenção } \\
\end{array}$ & $\begin{array}{l}\text { O geossítio é utilizado } \\
\text { esporadicamente para } \\
\text { atividades religiosas, mas não } \\
\text { é esta sua principal função }\end{array}$ & $\begin{array}{c}\text { O geossítio é utilizado por } \\
\text { muitos anos e com frequência } \\
\text { como ponto de peregrinação ou } \\
\text { para atividades religiosas }\end{array}$ \\
\hline \multirow{5}{*}{$\begin{array}{l}\text { Valor } \\
\text { estético }\end{array}$} & Vest1 & Coerência & $\begin{array}{l}\text { Diz respeito às características da } \\
\text { organização dos elementos } \\
\text { paisagisticos (em relação ao relevo, } \\
\text { vegetação, massas de água, e uso } \\
\text { do solo), não por serem exatamente } \\
\text { iguais, mas por apresentarem um } \\
\text { padraao específico que se repete e } \\
\text { diferencia aquela unidade. }\end{array}$ & $\begin{array}{l}\text { O geossítio não } \\
\text { apresenta nenhuma } \\
\text { coerência }\end{array}$ & $\begin{array}{l}\text { O geossítio apresenta um } \\
\text { baixo grau de coerência }\end{array}$ & $\begin{array}{l}\text { O geossítio I apresenta um } \\
\text { moderado grau de coerência }\end{array}$ & $\begin{array}{l}\text { O geossítio apresenta um alto } \\
\text { grau de coerência }\end{array}$ \\
\hline & Vest2 & Complexidade & $\begin{array}{c}\text { Corresponde à diversidade, à } \\
\text { variedade paisagística de um local, } \\
\text { podendo ser expressa pelo efeito } \\
\text { paisagístico causado pelos } \\
\text { elementos naturais como contraste } \\
\text { da topografia, a água, a vegetação, } \\
\text { etc }\end{array}$ & $\begin{array}{l}\text { O geossítio apresenta- } \\
\text { se extremamente } \\
\text { homogêneo quanto à } \\
\text { composição de } \\
\text { elementos }\end{array}$ & $\begin{array}{l}\text { O geossítio apresenta um } \\
\text { baixo grau de complexidade }\end{array}$ & $\begin{array}{l}\text { O geossítio apresenta um } \\
\text { moderado grau de } \\
\text { complexidade }\end{array}$ & $\begin{array}{l}\text { O geossítio apresenta um alto } \\
\text { grau de complexidade }\end{array}$ \\
\hline & Vest3 & Legibilidade & $\begin{array}{l}\text { Corresponde à organização das } \\
\text { formas percebidas na paisagem, as } \\
\text { partes que puderem ser } \\
\text { reconhecidas (legiveis) e } \\
\text { organizadas apresentam maior grau } \\
\text { de valor para a mente humana }\end{array}$ & $\begin{array}{l}\text { O geossítio apresenta } \\
\text { uma baixissima } \\
\text { legibilidade }\end{array}$ & $\begin{array}{l}\text { O geossitio apresenta um } \\
\text { baixo grau de legibilidade }\end{array}$ & $\begin{array}{l}\text { O geossitio apresenta um } \\
\text { moderado grau de } \\
\text { legibilidade }\end{array}$ & $\begin{array}{l}\text { O geossítio apresenta um alto } \\
\text { grau de legibilidade }\end{array}$ \\
\hline & Vest4 & Cores & $\begin{array}{l}\text { Valores e preferências } \\
\text { correspondem à interpretaçãão que } \\
\text { se dá às cores em cada cena. A } \\
\text { homogeneidade de cores diminui o } \\
\text { caráter de satisfação visual da } \\
\text { paisagem do ponto de vista } \\
\text { interpretativo enquanto que a maior } \\
\text { diversidade de cores aumenta esse } \\
\text { caráter (visualmente) }\end{array}$ & $\begin{array}{l}\text { Paisagem com um } \\
\text { elevado grau de } \\
\text { homogeneidade quanto } \\
\text { à variação de cores, } \\
\text { passando a ideia de } \\
\text { local monocromático }\end{array}$ & $\begin{array}{l}\text { Paisagem com a } \\
\text { predominância de uma cor } \\
\text { em relaçẫo às outras }\end{array}$ & $\begin{array}{l}\text { Paisagem apresenta cores } \\
\text { em proporçōes equivalentes } \\
\text { em sua composiçẫo }\end{array}$ & $\begin{array}{l}\text { Paisagem com grande } \\
\text { diversidade de cores e } \\
\text { contrastes }\end{array}$ \\
\hline & Vest5 & Bacia visual & $\begin{array}{l}\text { Locais que proporcionam alto grau } \\
\text { de visibilidade do entorno } \\
\text { apresentam avaliaçōes mais } \\
\text { positivas }\end{array}$ & $\begin{array}{l}\text { O local apresenta um } \\
\text { baixo grau de } \\
\text { visibilidade, pois } \\
\text { permite a observação } \\
\text { somente dos elementos } \\
\text { do geossítio }\end{array}$ & $\begin{array}{l}\text { O local apresenta um certo } \\
\text { grau de visibilidade, } \\
\text { permitindo a observação de } \\
\text { alguns elementos além do } \\
\text { geossítio }\end{array}$ & $\begin{array}{l}\text { O local apresenta um } \\
\text { razoável grau de visibilidade } \\
\text { do entorno, possibilitando a } \\
\text { observação de pequenas } \\
\text { distâncias a partir do } \\
\text { geossitio }\end{array}$ & $\begin{array}{c}\text { O local apresenta um alto grau } \\
\text { de visibilidade do entorno, } \\
\text { possibilitando a observação de } \\
\text { grandes distâncias a partir do } \\
\text { geossitio }\end{array}$ \\
\hline \multirow{7}{*}{$\begin{array}{l}\text { Valor de } \\
\text { uso }\end{array}$} & Vuso1 & Acessibilidade & $\begin{array}{l}\text { Indicativo das condições de acesso } \\
\text { ao local }\end{array}$ & $\begin{array}{l}\text { O geossítio possui } \\
\text { acesso apenas por } \\
\text { trilhas e veículos } \\
\text { tradicionais }\end{array}$ & $\begin{array}{l}\text { O geossítio possui acesso } \\
\text { restrito à estrada vicinal, } \\
\text { porém, garantindo a chegada } \\
\text { por ônibus }\end{array}$ & $\begin{array}{l}\text { O geossítio está localizado a } \\
\text { menos de } 200 \mathrm{~m} \text { de estrada } \\
\text { asfaltada }\end{array}$ & $\begin{array}{l}\text { O geossítio está localizado a } \\
\text { menos de } 100 \mathrm{~m} \text { de estrada } \\
\text { asfaltada }\end{array}$ \\
\hline & Vuso2 & $\begin{array}{c}\text { Potencial } \\
\text { interpretativo }\end{array}$ & $\begin{array}{l}\text { Relacionado com a capacidade dos } \\
\text { elementos presentes no geossitio } \\
\text { serem compreendidos por pessoas } \\
\text { sem conhecimento geológico }\end{array}$ & $\begin{array}{c}\text { O público necessita ter } \\
\text { conhecimento geológico } \\
\text { sólido para } \\
\text { compreender os } \\
\text { elementos }\end{array}$ & $\begin{array}{c}\text { O público necessita ter } \\
\text { conhecimento básico quanto } \\
\text { à geologia para compreender } \\
\text { os elementos }\end{array}$ & $\begin{array}{l}\text { O público necessita ter um } \\
\text { mínimo de conhecimento } \\
\text { geológico para compreender } \\
\text { os elementos }\end{array}$ & $\begin{array}{l}\text { O geossítio apresenta } \\
\text { elementos geológicos de uma } \\
\text { forma muito clara e expressiva } \\
\text { para todo o tipo de público }\end{array}$ \\
\hline & Vuso3 & $\begin{array}{c}\text { Valor } \\
\text { adicional } \\
\text { associado }\end{array}$ & $\begin{array}{l}\text { Refere-se a utilização do local para } \\
\text { atividades recreativas como } \\
\text { esportes de aventura }\end{array}$ & $\begin{array}{c}\text { O geossítio não } \\
\text { apresenta possibilidade } \\
\text { de utilização para fins } \\
\text { recreativos }\end{array}$ & $\begin{array}{l}\text { O geossítio pode vir a ser } \\
\text { utilizado para atividades } \\
\text { recreativas caso ocoorram } \\
\text { intervençōes na área } \\
\end{array}$ & $\begin{array}{l}\text { O geossítio necessita de } \\
\text { recuperação na infraestrutura } \\
\text { para voltar a ser utilizado } \\
\text { para fins recreativos }\end{array}$ & $\begin{array}{l}\text { O geossítio já é utilizado para } \\
\text { práticas recreativas }\end{array}$ \\
\hline & Vuso4 & $\begin{array}{l}\text { Serviços de } \\
\text { interpretação }\end{array}$ & $\begin{array}{c}\text { Corresponde a presença de centros } \\
\text { interpretativos ou locais que } \\
\text { disponibilizam informaçōes acerca } \\
\text { do geopatrimônio nas proximidades } \\
\text { do geossitios }\end{array}$ & $\begin{array}{l}\text { Não há centro } \\
\text { interpretativo ou local } \\
\text { com esta função nas } \\
\text { proximidades }\end{array}$ & $\begin{array}{l}\text { Há um centro interpretativo } \\
\text { ou local com a mesma função } \\
\text { a alguns quilômetros }\end{array}$ & $\begin{array}{c}\text { Há um centro interpretativo } \\
\text { ou local com a mesma função } \\
\text { a menos de } 500 m \text { do } \\
\text { geossitio }\end{array}$ & $\begin{array}{l}\text { Há um centro interpretativo ou } \\
\text { local com a mesma função a } \\
\text { menos de } 100 \mathrm{~m} \text { do geossítio }\end{array}$ \\
\hline & Vuso5 & $\begin{array}{l}\text { Serviços } \\
\text { básicos }\end{array}$ & $\begin{array}{c}\text { Relacionado à presença de locais } \\
\text { que realizam a venda de } \\
\text { suprimentos básicos como água e } \\
\text { alimentos nas proximidades do } \\
\text { geossítio }\end{array}$ & $\begin{array}{l}\text { Não há nenhum local } \\
\text { que realize venda de } \\
\text { suprimentos básicos }\end{array}$ & $\begin{array}{l}\text { Há um local que realiza a } \\
\text { venda de suprimentos } \\
\text { básicos a menos de } 5 \mathrm{~km} \text { do } \\
\text { geossítio }\end{array}$ & $\begin{array}{l}\text { Há um local que realiza a } \\
\text { venda de suprimentos } \\
\text { básicos a menos de } 2 \mathrm{Km} \text { do } \\
\text { geossítio }\end{array}$ & $\begin{array}{l}\text { Há um local que realiza a venda } \\
\text { de suprimentos básicos a } \\
\text { menos de } 500 \mathrm{~m} \text { do geossítio }\end{array}$ \\
\hline & Vuso6 & Infraestrutura & $\begin{array}{l}\text { Indicativo da presença de } \\
\text { infraestrutura que facilite ou sirva de } \\
\text { apoio para a utilização do local } \\
\text { (equipamentos primários como } \\
\text { escadas, trapiches para mirantes, } \\
\text { grades de proteçãa) }\end{array}$ & $\begin{array}{l}\text { Geossítio sem } \\
\text { infraestrutura }\end{array}$ & $\begin{array}{l}\text { Geossítio com infraestrutura } \\
\text { rudimentar e sem boas } \\
\text { condiçōes de uso }\end{array}$ & $\begin{array}{l}\text { Geossitio com infraestrutura } \\
\text { mas nem todos equipamentos } \\
\text { primários estão em boas } \\
\text { condiçōes de uso }\end{array}$ & $\begin{array}{l}\text { Geossítio com infraestrutura e } \\
\text { com equipamentos primários } \\
\text { em boas condiçōes de uso }\end{array}$ \\
\hline & Vuso7 & Logística & $\begin{array}{c}\text { Indicativo da presença de locais } \\
\text { para hospedagem, alimentação e } \\
\text { serviços de saúde com capacidade } \\
\text { global nas proximidades do } \\
\text { geossítio }\end{array}$ & $\begin{array}{c}\text { Hospedagem e } \\
\text { restaurantes para } \\
\text { grupos de } 30 \text { pessoas a } \\
\text { mais de } 20 \mathrm{Km} \text { de } \\
\text { distância do geossítio }\end{array}$ & $\begin{array}{c}\text { Hospedagem e restaurantes } \\
\text { para grupos de } 30 \text { pessoas a } \\
\text { menos de } 20 \mathrm{~km} \text { de distância } \\
\text { do geossítio }\end{array}$ & $\begin{array}{c}\text { Hospedagem e restaurantes } \\
\text { para grupos de } 30 \text { pessoas a } \\
\text { menos de } 15 \mathrm{~km} \text { de distância } \\
\text { do geossitio }\end{array}$ & $\begin{array}{l}\text { Hospedagem e restaurantes } \\
\text { para grupos de } 50 \text { pessoas a } \\
\text { menos de } 10 \mathrm{~km} \text { de distância } \\
\text { do geossítio }\end{array}$ \\
\hline
\end{tabular}


Quadro 3: Critérios, sub-critérios e parâmetros envolvidos na quantificação do risco de degradação de determinado geossítio Fonte: ZIEMANN (2016).

\begin{tabular}{|c|c|c|c|c|c|c|c|}
\hline $\begin{array}{c}\text { Risco de } \\
\text { Degradação }\end{array}$ & & & Descrição & 0 & 1 (Bom) & 5 (Moderado) & 10 (Ruim) \\
\hline \multirow{6}{*}{$\begin{array}{c}\text { Risco } \\
\text { associado }\end{array}$} & R1 & $\begin{array}{c}\text { Vulnerabilidade } \\
\text { natural }\end{array}$ & $\begin{array}{c}\text { Refere-se à vulnerabilidade do } \\
\text { geossitio face à ocorrencia de } \\
\text { processos naturais atuantes no } \\
\text { local, que podem afetá-lo }\end{array}$ & $\begin{array}{c}\text { Não apresenta qualquer } \\
\text { vulnerabilidade } \\
\text { decorrente de } \\
\text { processos naturais }\end{array}$ & $\begin{array}{c}\text { Baixa vulnerabilidade } \\
\text { natural, porém em escala } \\
\text { que não compromete os } \\
\text { aspectos relevantes do local }\end{array}$ & $\begin{array}{c}\text { Apresenta alguma } \\
\text { vulnerabilidade, porém tais } \\
\text { transformaçōes podem ser } \\
\text { mitigadas através de medidas } \\
\text { simples }\end{array}$ & $\begin{array}{c}\text { Elevada vulnerabilidade } \\
\text { decorrente da atividade de } \\
\text { processos naturais }\end{array}$ \\
\hline & R2 & Fragilidade & $\begin{array}{l}\text { Potencial de destruição do } \\
\text { geossítio dentro da escala humana } \\
\text { de tempo, ligado às suas } \\
\text { características estruturais } \\
\text { intrínsecas. }\end{array}$ & $\begin{array}{c}\text { Aspectos } \\
\text { geomorfológicos que } \\
\text { pelas suas grandes } \\
\text { dimensóes, relevo, etc, } \\
\text { são dificilmente } \\
\text { afetados }\end{array}$ & $\begin{array}{c}\text { Grandes estruturas } \\
\text { geológicas que só podem } \\
\text { ser afetadas por grandes } \\
\text { processos naturais, porém a } \\
\text { possibilidade de sua } \\
\text { destruição é considerada } \\
\text { pouco provável }\end{array}$ & $\begin{array}{l}\text { Aspectos estruturais, } \\
\text { formações sedimentares ou } \\
\text { rochosas de dimensões } \\
\text { decamétricas, com algum grau } \\
\text { de fragilidade que podem ser } \\
\text { destrúdas por pequenos } \\
\text { processos naturais ou humanos }\end{array}$ & $\begin{array}{l}\text { Aspectos de dimensão } \\
\text { métrica, com elevado } \\
\text { grau de fragilidade e que } \\
\text { podem ser destruídos por } \\
\text { pequenos processos } \\
\text { naturais ou humanos }\end{array}$ \\
\hline & R3 & $\begin{array}{l}\text { Regime de } \\
\text { propriedade }\end{array}$ & $\begin{array}{l}\text { Refere-se à proteção legal que o } \\
\text { geossítio pode estar submetido e } \\
\text { às condiçōes de acesso (em } \\
\text { relaçâao ao controle de visitas) }\end{array}$ & $\begin{array}{l}\text { Geossítio localizado em } \\
\text { uma área com proteção } \\
\text { legal e controle de } \\
\text { acesso }\end{array}$ & $\begin{array}{c}\text { Geossítio localizado em } \\
\text { uma área com proteção } \\
\text { legal, mas nenhum controle } \\
\text { de acesso }\end{array}$ & $\begin{array}{l}\text { Geossítio localizado em uma } \\
\text { área sem proteção legal, mas } \\
\text { com controle de acesso }\end{array}$ & $\begin{array}{l}\text { Geossítio localizado em } \\
\text { uma área sem proteção } \\
\text { legal e sem controle de } \\
\text { acesso }\end{array}$ \\
\hline & R4 & $\begin{array}{l}\text { Vulnerabilidade } \\
\text { antrópica }\end{array}$ & $\begin{array}{l}\text { Risco de degradação causado } \\
\text { pelas atividades humanas que } \\
\text { afetam diretamente o geossítio }\end{array}$ & $\begin{array}{l}\text { Geossítio localizado em } \\
\text { área com difícil acesso } \\
\text { e fiscalização }\end{array}$ & $\begin{array}{l}\text { Geossítio localizado em } \\
\text { área com difícil acesso mas } \\
\text { sem controle }\end{array}$ & $\begin{array}{c}\text { Geossítio localizado em área } \\
\text { pouco acessivel, mas propícia } \\
\text { à exploração econômica e } \\
\text { coleta de materiais }\end{array}$ & $\begin{array}{c}\text { Geossítio localizado em } \\
\text { área acessível e propícia } \\
\text { à exploração econômica e } \\
\text { coleta de materiais, sem } \\
\text { controle de acesso } \\
\end{array}$ \\
\hline & R5 & Uso atual & $\begin{array}{l}\text { Indica as condições atuais de } \\
\text { utilização do geossito, em relação à } \\
\text { visitação }\end{array}$ & $\begin{array}{l}\text { O geossítio não possui } \\
\text { uso ligado à visitação } \\
\text { (turística ou didática) }\end{array}$ & $\begin{array}{l}\text { O geossítio possui alguma } \\
\text { taxa de visitação, porém } \\
\text { incipiente }\end{array}$ & $\begin{array}{l}\text { O geossítio possui uma taxa de } \\
\text { visitação em periodos } \\
\text { esporádicos }\end{array}$ & $\begin{array}{l}\text { O geossítio possui um alta } \\
\text { taxa de visitação durante } \\
\text { todo ano }\end{array}$ \\
\hline & R6 & $\begin{array}{c}\text { Proximidade de } \\
\text { áreas/atividades } \\
\text { com potencial } \\
\text { para causar } \\
\text { degradação }\end{array}$ & $\begin{array}{l}\text { Indicativo da proximidade do } \\
\text { geossítio com alguma área que } \\
\text { possa causar degradação }\end{array}$ & $\begin{array}{c}\text { Geossítio não está } \\
\text { próximo a alguma } \\
\text { potencial árealatividade } \\
\text { degradante }\end{array}$ & $\begin{array}{c}\text { Geossitio localizado a } \\
\text { menos de } 500 \mathrm{~m} \text { de uma } \\
\text { potencial área/atividade } \\
\text { degradante }\end{array}$ & $\begin{array}{l}\text { Geossítio localizado a menos } \\
\text { de } 200 \mathrm{~m} \text { de uma potencial } \\
\text { área/atividade degradante }\end{array}$ & $\begin{array}{c}\text { Geossítio lozalizado a } \\
\text { menos de } 50 \mathrm{~m} \text { de uma } \\
\text { potencial área/atividade } \\
\text { degradante }\end{array}$ \\
\hline $\begin{array}{l}\text { Estado de } \\
\text { conservação }\end{array}$ & C1 & Situação atual & $\begin{array}{l}\text { Relacionado ao atual estado de } \\
\text { conservação do geossítio e à } \\
\text { existência ou inexistência de gestão }\end{array}$ & $\begin{array}{l}\text { O local está conservado } \\
\text { e possui medidas de } \\
\text { gestão }\end{array}$ & $\begin{array}{l}\text { O local é utilizado e possui } \\
\text { poucos problemas que } \\
\text { podem ser facilmente } \\
\text { mitigáveis mediante } \\
\text { medidas simples de } \\
\text { intervenção }\end{array}$ & $\begin{array}{l}\text { O local é utilizado e apresenta } \\
\text { alguns problemas que podem } \\
\text { ser mitigados mediante } \\
\text { medidas moderadas de } \\
\text { intervenção }\end{array}$ & $\begin{array}{c}\text { O local encontra-se em } \\
\text { total estado de abandono, } \\
\text { possui muitos problemas } \\
\text { de conservação, com } \\
\text { muitos danos } \\
\text { permanentes }\end{array}$ \\
\hline
\end{tabular}

Quadro 4: Pesos para o cálculo da potencialidade geoturística e para o risco de degradação

\begin{tabular}{|c|c|c|}
\hline Potencial Geoturístico & & $100 \%$ \\
\hline \multirow{7}{*}{ Valor geocientífico } & Local tipo & \multirow{7}{*}{$20 \%$} \\
\hline & Raridade & \\
\hline & Grau de conhecimento científico & \\
\hline & Integridade & \\
\hline & Relevância didática & \\
\hline & Associação de elementos & \\
\hline & Acessibilidade & \\
\hline \multirow{2}{*}{ Valor cultural } & Valor de memória & \multirow{2}{*}{$20 \%$} \\
\hline & Valor espiritual & \\
\hline \multirow{5}{*}{ Valor estético } & Coerência & \multirow{5}{*}{$40 \%$} \\
\hline & Complexidade & \\
\hline & Legibilidade & \\
\hline & Cores & \\
\hline & Bacia visual & \\
\hline \multirow{7}{*}{ Valor de uso } & Acessibilidade & \multirow{7}{*}{$20 \%$} \\
\hline & Potencial interpretativo & \\
\hline & Valor adicional associado & \\
\hline & Serviços de interpretação & \\
\hline & Serviços básicos & \\
\hline & Infraestrutura & \\
\hline & Logística & \\
\hline
\end{tabular}

\begin{tabular}{|c|c|c|}
\hline $\begin{array}{c}\text { Risco de } \\
\text { Degradação }\end{array}$ & & $100 \%$ \\
\hline \multirow{6}{*}{$\begin{array}{l}\text { Risco } \\
\text { Associado }\end{array}$} & Vulnerabilidade natural & \multirow{6}{*}{$50 \%$} \\
\hline & Fragilidade & \\
\hline & Regime de propriedade & \\
\hline & Vulnerabilidade Antrópica & \\
\hline & Uso atual & \\
\hline & $\begin{array}{c}\text { Proximidade a } \\
\text { áreas/atividades potenciais } \\
\text { para causar degradação }\end{array}$ & \\
\hline $\begin{array}{c}\text { Estado de } \\
\text { conservação }\end{array}$ & Situação atual & $50 \%$ \\
\hline
\end{tabular}




\section{RESULTADOS}

Ao longo do ano de 2015 foram realizados trabalhos de campo envolvendo os 43 geossítios préselecionados, com vistas à caracterização dos mesmos e ao levantamento das informações que permitissem a avaliação qualitativa, conforme apresentado no Quadro 5.

Após realizada a avaliação qualitativa, procedeu-se ao cálculo dos 21 sub-critérios, agrupados em quatro critérios principais que envolvem o Potencial geoturístico (valor geocientífico, valor estético, valor cultural e valor de uso), bem como dos 7 sub-critérios agrupados em dois critérios principais (Risco Associado e Estado de Conservação) que envolvem o Risco de Degradação. A partir destes cálculos, foi possível chegar-se à definição do Índice de Aproveitamento Geoturístico dos locais inventariados, considerando-se este, como já assinalado anteriormente, como o resultado da subtração do Risco de Degradação do Potencial Geoturístico do geossítio.

Dos 43 geossítios inventariados, obteve-se um resultado positivo para o aproveitamento geoturístico em 24 deles. Nestes locais a acessibilidade é facilitada, há ocorrência de uma associação de elementos, além de serem locais com uma raridade considerável e com sua integridade preservada. Diante disso, estes geossítios caracterizam-se como locais com condições facilitadas para utilização geoturística devido ao fato de requererem menores intervenções para o aproveitamento geoturístico imediato. Por outro lado, 19 geossítios apresentaram pontuações negativas para o aproveitamento geoturístico com as condições em que se encontram, sendo geossítios com menores condições de utilização geoturística sem que antes ocorram intervenções logísticas importantes (Quadro 6 e Figura 3). Destacam-se aqui os geossítios de interesse paleontológicos, uma ravina com grandes proporções e uma cascata. Tais locais atualmente estão sob fortes condições de ameaça sem que exista nenhuma medida de intervenção para mitigar problemas como erosão, coletas indiscriminadas de fósseis, exploração econômica, dispersão de espécies invasoras e vulnerabilidade natural. Os resultados obtidos nesta avaliação indicam o quanto prejudicial pode ser a exploração geoturística destes locais sem as devidas medidas de conservação. Os locais com o Risco de Degradação menor referem-se a grandes formações rochosas, como morros isolados, o que dificulta a degradação do patrimônio.

Dentre os 24 geossítios cujo índice de aproveitamento geoturístico resultou em valores expressivos, destaca-se a grande contribuição do patrimônio geomorfológico (Figura 4), envolvendo morros testemunho, importantes quedas d'água, além de uma escarpa de rochas vulcânicas, uma barra arenosa e uma caverna.

É comum a todos os geossítios avaliados a necessidade de intervenção com medidas primárias, envolvendo o aumento de infraestrutura, melhorias no acesso, sinalização e outros. Estas medidas devem ser pensadas de maneira a fornecer condições básicas ao turismo e também como condição para a conservação do local, pois se algum geossítio for degradado de forma significativa, este poderá não estar mais disponível para visitação, reduzindo o potencial de atratividade deste território. Além disso, é fundamental que, antes da implantação de roteiros geoturísticos que aumentem a atratividade do território, se desenvolva um plano interpretativo adequado, a fim de garantir o melhor aproveitamento educativo do potencial geoturístico representado pela paisagem em análise. 
Quadro 5. Avaliação qualitativa segundo os critérios estabelecidos para os geossítios pré-selecionados.

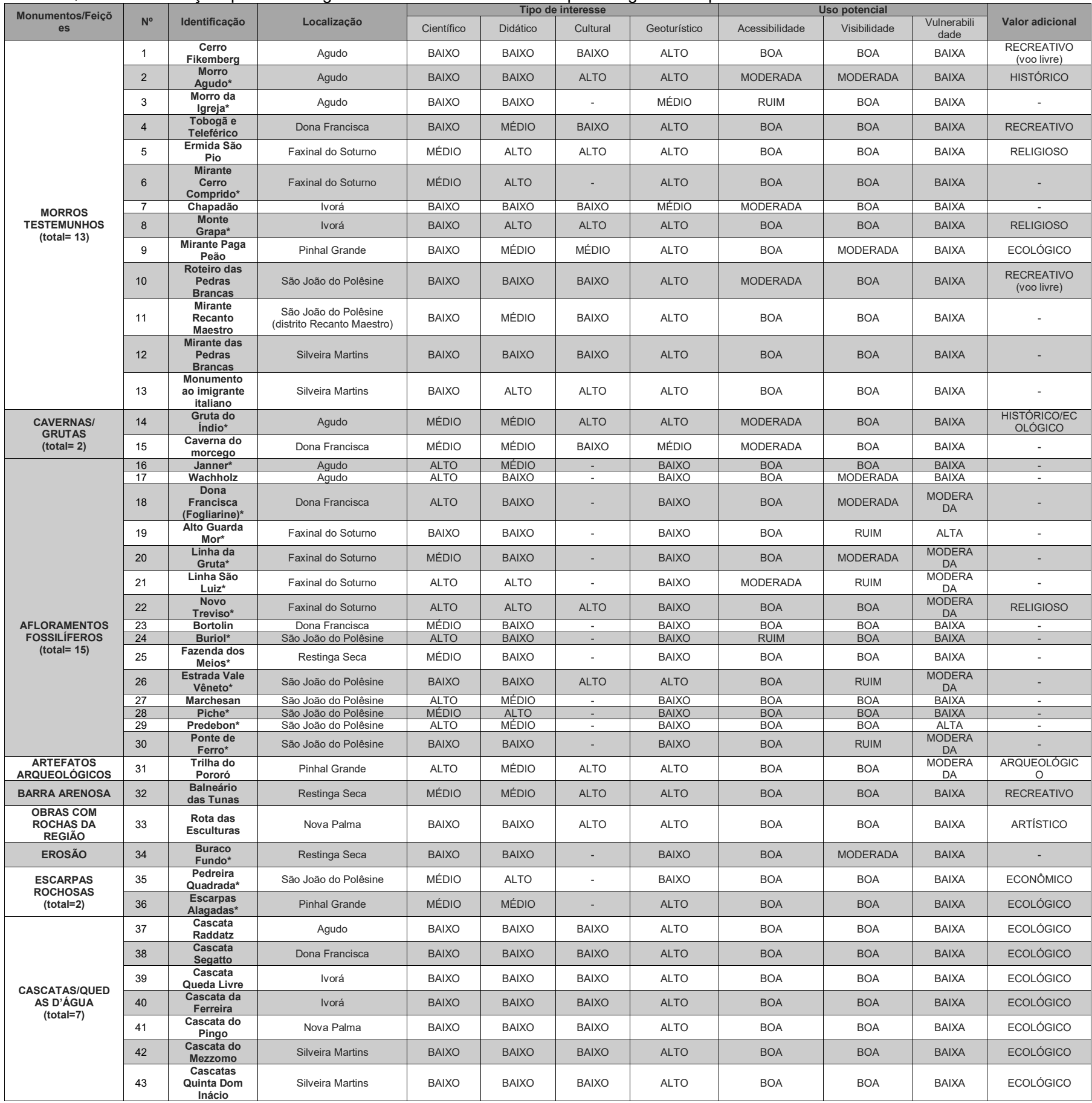

Fonte: ZIEMANN (2016). 
Quadro 6: Resultado do cálculo do Índice de Aproveitamento Geoturístico.

\begin{tabular}{|c|c|c|}
\hline \multicolumn{3}{|c|}{ PG - RD = IAGtur } \\
\hline Geossítios & PG - RD & IAGtur \\
\hline Cerro Finkemberg & $5,26-1,50$ & 3,76 \\
\hline Morro Agudo & $5,62-1,58$ & 4,04 \\
\hline Morro da Igreja & $2,97-1,50$ & 1,47 \\
\hline Tobogã e teleférico & $3,82-3,83$ & $-0,01$ \\
\hline Ermida São Pio & $5,72-1,50$ & 4,22 \\
\hline Mirante Cerro Comprido & $4,35-1,92$ & 2,43 \\
\hline Chapadão & $4,77-1,58$ & 3,19 \\
\hline Monte Grapa & $6,68-1,83$ & 4,85 \\
\hline Mirante Paga Peão & $5,51-3,16$ & 2,35 \\
\hline Roteiro das Pedras Brancas & $4,39-1,83$ & 2,56 \\
\hline Mirante Recanto Maestro & $4,22-1,50$ & 2,72 \\
\hline Mirante Pedras Brancas & $3,95-1,83$ & 2,12 \\
\hline Monumento ao Imigrante & $5,60-1,41$ & 4,19 \\
\hline Gruta do índio & $3,91-1,91$ & 2 \\
\hline Caverna do Morcego & $3,55-5,58$ & $-2,03$ \\
\hline Janner & $1,80-5,50$ & $-3,70$ \\
\hline Wachholz & $0,81-8,33$ & $-7,52$ \\
\hline Fogliarine & $1,94-5,91$ & $-3,97$ \\
\hline Alto Guarda Mor & $0,85-9,16$ & $-8,31$ \\
\hline Linha da Gruta & $0,85-9,16$ & $-8,31$ \\
\hline Linha São Luiz & $1,69-6,75$ & $-5,06$ \\
\hline Novo Treviso & $1,02-6,25$ & $-5,23$ \\
\hline Bortolin & $1,69-3$ & $-1,31$ \\
\hline Buriol & $2,09-4,58$ & $-2,49$ \\
\hline Fazenda dos Meios & $1,23-5$ & $-3,77$ \\
\hline Estrada Vale Vêneto & $1,35-9,58$ & $-8,23$ \\
\hline Marchesan & $1,41-6,75$ & $-5,34$ \\
\hline Piche & $1,43-2,75$ & $-1,32$ \\
\hline Predebon & $2,09-5,50$ & $-3,41$ \\
\hline Ponte de Ferro & $0,76-9,16$ & $-8,40$ \\
\hline Trilha do Pororó & $3,30-2,33$ & 0,97 \\
\hline Tunas & $5,33-2,33$ & 3 \\
\hline Rota das Esculturas & $4,53-2,33$ & 2,20 \\
\hline Buraco Fundo & $2,74-6,08$ & $-3,34$ \\
\hline Pedreira Quadrada & $1,72-3,91$ & $-2,19$ \\
\hline Escarpas Alagadas & $5,31-0,75$ & 4,56 \\
\hline Cascata Raddatz & $4,62-1,91$ & 2,71 \\
\hline Cascata do Segatto & $3,76-3,16$ & 0,60 \\
\hline Cascata Queda Livre & $3,76-1,50$ & 2,26 \\
\hline Cascata da Ferreira & $4,02-1,16$ & 2,86 \\
\hline Cascata do Pingo & $4,02-1,16$ & 2,86 \\
\hline Cascata do Mezzomo & $4,02-3,58$ & 0,44 \\
\hline Cascatas Quinta Dom Inácio & $4,68-1,92$ & 2,76 \\
\hline
\end{tabular}

Fonte: ZIEMANN (2016)

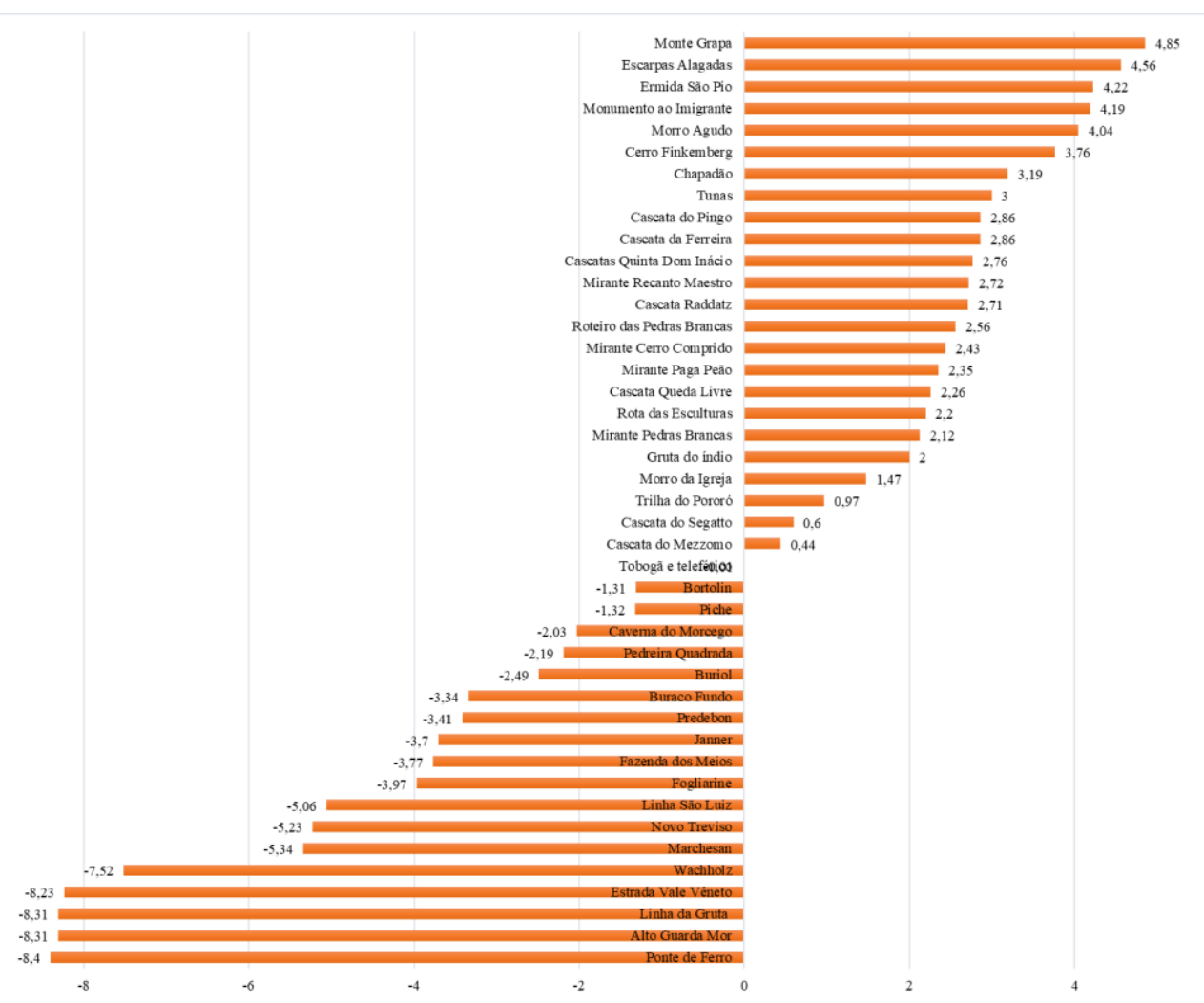

Figura 3: gráfico de representação do Índice de Aproveitamento Geoturístico para os 43 geossítios avaliados, onde se destacam os 24 geossítios com possibilidade de aproveitamento geoturístico (IAGtur >0). Fonte: ZIEMANN (2016). 

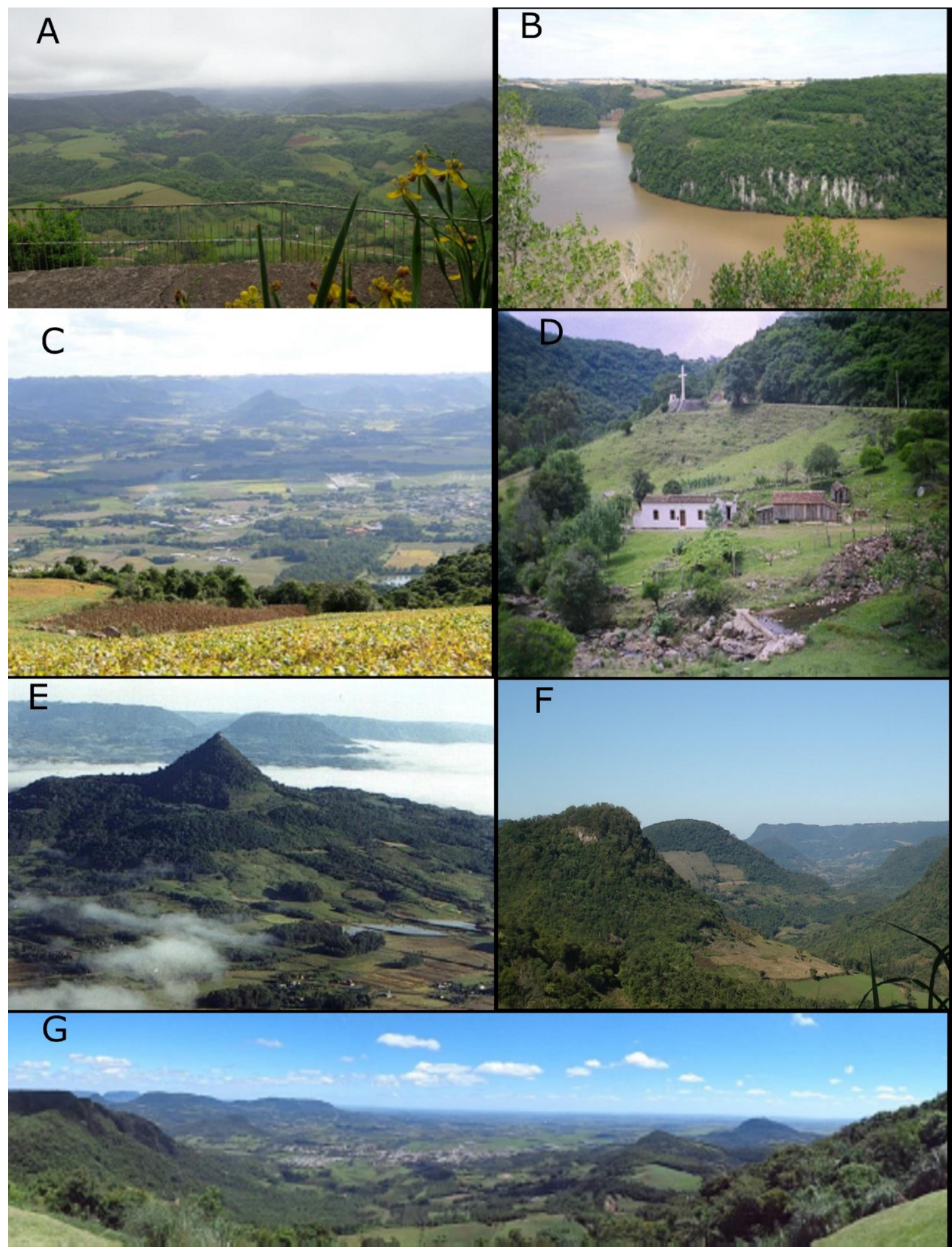

Figura 4: Fotos dos geossítios com os sete maiores índices de aproveitamento geoturístico no território do projeto Geoparque Quarta Colônia (A- Monte Grapa; B- Escarpas Alagadas; C- Ermida São Pio; D- Monumento ao Imigrante; E- Morro Agudo; F- Chapadão; G- Cerro Finkenberg). 


\section{CONSIDERAÇÕES FINAIS}

O geoturismo, quando planejado de forma adequada, apresenta-se como atividade capaz de proteger o geopatrimônio e auxiliar no desenvolvimento local da comunidade de áreas com grande geodiversidade, como é o caso do território do projeto Geoparque Quarta Colônia.

Todavia, para que essa atividade possa ser realizada da melhor maneira, devem ser implantadas medidas de gestão que correspondem à realidade de cada geossítio. O notável geopatrimônio identificado na Quarta Colônia, apesar de expor valores significativos quanto ao seu valor geoturístico e geocientífico, encontra-se sob condições de abandono, requerendo estratégias de gestão capazes de conservar e promover o território aspirante a uma candidatura de Geoparque na Rede Mundial.

A identificação e quantificação apresentadas neste trabalho buscaram apontar áreas prioritárias para o investimento de recursos em cada segmento (geoturístico, geocientífico e áreas com elevado risco de degradação), dentro do território do futuro geoparque, contudo, esta proposta não possui a intenção de ser uma receita pronta para ser aplicada a qualquer outro lugar; pelo contrário, considera-se que cada local apresenta suas características particulares e, assim, outras propostas devem ser consideradas, já que o principal objetivo da avaliação quali-quantitativa do geopatrimônio é o de auxiliar no processo de gestão de cada área, no sentido de estabelecer prioridades de investimento e de apontar os pontos mais sensíveis para a manutenção de uma atividade geoturística permanente. Assim, este artigo apresenta uma nova possibilidade de avaliação do aproveitamento geoturístico, considerando as potencialidades do território, mas sem esquecer dos riscos da utilização do geopatrimônio sem um adequado processo de monitoramento dos impactos resultantes.

\section{AGRADECIMENTOS}

A primeira autora deste artigo agradece a Fundação de Amparo a Pesquisa do Rio Grande do Sul (FAPERGS) pela bolsa de mestrado.

\section{REFERÊNCIAS}

BERNÁLDEZ, F. G. Invitación a la ecologia humana: La adaptación afectiva al entorno. Madrid:Editora GAR, 1985.

BRILHA, J. B. R. Patrimônio Geológico e Geoconservação: a conservação da natureza na sua vertente geológica. Braga: Palimage, 2005.

BRILHA, J. Inventory and quantitative assessment of geosites and geodiversity sites: a review. Geoheritage, 2015.

BORBA, A. W. Geodiversidade e geopatrimônio como bases para estratégias de geoconservação: conceitos, abordagens, métodos de avaliação e aplicabilidade no contexto do estado do Rio Grande do Sul. Pesquisas em geociências, v.38, p. 3-14, 2011.

FARSANI, N. T.; COELHO, C.; COSTA, C. Geotourism and Geoparks as Novel Strategies for Socioeconomic Development in Rural Areas. International Journal of Tourism Research. (13): 68-81,2011.

GARCÍA-CORTÉS A. \& URQUí L. C. -2009- Documento metodológico para la elaboración del inventario Español de lugares de interés geológico (IELIG). Version 11, 12-03-2009. Instituto Geológico y Minero de España. Disponível em: http://w.igme.es/ internet/patrimonio/, acessado em: 23/Set/15.

GARCÍA-ORTIZ, Esperanza; FUERTES-GUTIÉRREZ, Inés; FERNÁNDEZ-MARTÍNEZ, Esperanza. Concepts and terminology for the risk of degradation of geological heritage sites: fragility and natural vulnerability, a case study.Proceedings of the Geologists' Association, v. 125, n. 4, 2014.

GODOY, M. M.; BINOTTO, R. B.; SILVA, R. C. da; ZERFASS, H. Geoparques/propostas: Quarta Colônia (RS). In: SCHOBBENHAUS, C.; SILVA, C. R. da (Org.). Geoparques do Brasil: propostas. Rio de Janeiro: CPRM, 2012. p. 417-456. 
LANGER, M. C.; RIBEIRO, A. M.; SCHULTZ, C. L.; FERIGOLO, J. The continental tetrapod-bearing Triassic of south Brazil. New Mexico Museum of Natural History and Science Bulletin, v.41, p.201-218, 2007.

LIMA, F.F.; BRILHA, J.B.; SALAMUNI, E. Inventorying Geological Heritage in Large Territories: A Methodological Proposal Applied to Brazil. Geoheritage, v.2, p.91-99, 2010.

LORO, N. S.; COELHO, E. R. B. As festas religiosas e o turismo na Quarta Colônia imperial de imigração italiana, RS: As razões dos freqüentadores das festas. Disciplinarum Scientia, v.6, p.111-120, 2010.

PEREIRA, P. J. DA S. Patrimônio Geomorfológico: conceptualização, avaliação e divulgação. Aplicação ao Parque Natural de Montesinho. Tese de Doutoramento (Doutorado em Ciências). Universidade do Minho. Portugal, 2006.

PEREIRA, R. G. F. de A. Geoconservação e Desenvolvimento Sustentável na Chapada Diamantina (Bahia - Brasil). Tese de Doutoramento (Doutorado em Ciências). Universidade do Minho. Portugal, 2010.

SANTOS, N. R. Z dos; CERETTA, C. C.; ZIEMANN, D. R. Cafés coloniais como referência e atrativo turístico no município de Agudo-RS/Brasil. Geografia Ensino \& Pesquisa, v.19, p.39-48, 2015.

VALCARCE, E. G.; CORTÉS, A. G. El patrimônio geológico: Bases para su valorición, protección, conservación y utilización. In: Dirección General de Información y Evaluación Ambiental. Madrid: Ministério de Obras Públicas, Transportes e Medio Ambiente, 1996. p.11-16.

ZERFASS, H. Geologia da Folha de Agudo, SH.22-V-C-V, escala 1:100.000. Serviço Geológico do Brasil-CPRM, CD-ROM, 2007.

ZIEMANN, D. R. Estratégias de geoconservação para a proposta do Geoparque Quarta ColôniaRS. Dissertação de mestrado (Mestrado em Geografia). Universidade Federal de Santa Maria. Santa Maria, 2016.

ZIMMER, P.; GRASSMANN, S. Guia para avaliar o potencial turístico de um território. Espanha: Leader European Observatory, 1996. 